Gut, 1973, 14, 627-630

\title{
Inheritance and influence of histocompatibility (HL-A) antigens in adult coeliac disease
}

\author{
P. L. STOKES, P. ASQUith, G. K. T. HOLMES, PAUline MACKINTOSH, AND \\ W. T. COOKE ${ }^{1}$
}

\begin{abstract}
From the Nutritional and Intestinal Unit, The General Hospital, Birmingham, the Department of Experimental Pathology, The University of Birmingham, and the Regional Blood Transfusion Centre, Birmingham
\end{abstract}

SUMMARY In a study of histocompatibility antigens in adult coeliac disease the HL-A phenotypes have been determined in 117 patients and 149 of their first-degree relatives, of whom 94 had had a jejunal biopsy performed. There was an increased frequency of the HL-A 8 antigen in the patients and their relatives. Family studies showed no irregularity in the inheritance of both this antigen and the HL-A 1 and 8 haplotype.

It has recently been established by two independent groups that there is an unusual distribution of certain histocompatibility (HL-A) antigens in patients with adult coeliac disease. Falchuk and coworkers found that HL-A 8 antigen was present in $87.5 \%$ of coeliac patients compared with $21.5 \%$ of controls (Falchuk, Rogentine, and Strober, 1972), percentages similar to those found in our study which were 87.8 and $29.5 \%$ respectively (Stokes, Asquith, Holmes, Mackintosh, and Cooke, 1972a). Although the frequency of HL-A 1 was increased in both of these studies, it has been suggested that as there is a known genetic association between HL-A 8 and HL-A 1 (Cavalli-Sforza and Bodmer, 1971), this increase of HL-A 1 may simply reflect the increased frequency of HL-A 8 (Falchuk et al, 1972).

The observation of an increased frequency of HL-A 8 antigen in coeliac disease may be important for several reasons. The high frequency of malignancy in coeliac disease (Harris, Cooke, Thompson, and Waterhouse, 1967) raises the question of whether there is a causal relationship between altered frequencies of HL-A antigens and a malignant predisposition in man as has been described in animals (Lilly, Boyse, and Old, 1964). Again in animals, genes determining histocompatibility antigens are closely associated with those responsible for determining immune responses (McDevitt and Bodmer, 1972); altered frequencies of HL-A antigens could therefore support an immunological aetiology of the

${ }^{1}$ Correspondence to W.T.C.

Received for publication 9 May 1973. disease. As HL-A antigens are of predictable inheritance, an opportunity exists to study the inheritance of the disease from a new viewpoint. Coeliac disease is known to be familial in some instances although the mode of inheritance has not been clearly defined (MacDonald, Dobbins, and Rubin, 1965). It is also recognized that quite frequently the disease may produce few symptoms and in such instances a jejunal biopsy is necessary for its exclusion.

This paper reports the results of HL-A antigen determinations in coeliac patients and in their firstdegree relatives many of whom have had a jejunal biopsy performed.

\section{Patients and Methods}

One hundred and seventeen unrelated patients with well documented coeliac disease having a characteristic jejunal biopsy were studied. This group included the 49 patients previously reported. One hundred and forty-nine first-degree relatives of 58 of these patients had their HL-A phenotypes determined and these included 101 relatives of 46 of the propositi who were HL-A 8. Fifty-two male and 42 female relatives had a jejunal biopsy performed at or within $5 \mathrm{~cm}$ beyond the ligament of Trietz using a modified Choudhury-Cooke-Nicholson capsule (Roy Choudhury, Nicholson, and Cooke, 1964) and the data relevant to the inheritance of coeliac disease, as distinct from that of HL-A antigens, relate to this group alone. Any relative having the classical grade III abnormality (Roy Choudhury, Cooke, Tan, Banwell, and Smits, 1966) is regarded as having coeliac 
disease. Nine families were studied in which HL-A antigens were known in both parents and at least two children thus allowing the determination of haplotypes. In addition there were other families in which the distribution of HL-A antigens was such that the haplotypes and their mode of inheritance could be deduced.

A control group consisting of 159 healthy subjects and 109 potential donors for a renal transplant programme has been used. There was no significant difference between the healthy subjects and the potential donors with respect to HL-A frequencies (Stokes, Asquith, Holmes, Mackintosh, and Cooke, 1972b).

Twelve HL-A specificities were determined using a modification of the microlymphocytotoxic method of Terasaki and McClelland (1964).

\section{Results}

Table I shows the frequencies of the $12 \mathrm{HL}-\mathrm{A}$ specificities in the 117 propositi with coeliac disease and in the 268 controls. A statistically significant increase in the frequencies of the HL-A 8 and HL-A 1 antigens was found $(P<0.001)$. Based simply upon the phenotypes there was also an increase in the combination of HL-A 8 and HL-A 1 compared with con- trols even when allowance is made for the number of comparisons $(\mathrm{P}<0.001)$ (Miller, 1966).

Of the 58 coeliac patients who formed the propositi for the family study, 46 had the HL-A 8 antigen. The results of HL-A typing in their 101 firstdegree relatives is shown in table II. There were eight families in which both parents of an HL-A 8 coeliac propositus were typed. The father was HL-A 8 in all of the families as was the mother in five of them, so that in five of the eight families both parents were HL-A 8.

The haplotypes were known in 15 unrelated coeliac patients of whom 12 had the haplotype 1 and 8 . Family trees of six of these latter patients appear in fig 1 which also shows the result of jejunal biopsy where performed. The HL-A antigens are shown for each member of the families and are joined together to indicate their association as haplotypes. Three coeliac parents having the 1 and 8 haplotype, one in each of families I and III, passed on the haplotype to a total of five children who were biopsied yet none of these have coeliac disease. In family III a coeliac son did not inherit the 1 and 8 haplotype from his coeliac father. Two of his siblings who did inherit the 1 and 8 haplotype from the affected parent do not have coeliac disease. In family IV an unaffected father who has the 1 and 8 haplotype passed it on to

\begin{tabular}{|c|c|c|c|c|}
\hline \multicolumn{2}{|c|}{$H L-A$ Antigen } & $\begin{array}{l}\text { Adult Coeliac }(n=117) \\
\text { Disease }\end{array}$ & Controls $(n=268)$ & $\begin{array}{l}\text { Probability }\left(\chi^{2} \text { Test }\right) \\
0.001\end{array}$ \\
\hline Locus 1 & $\begin{array}{r}1 \\
2 \\
3 \\
9 \\
10 \\
11\end{array}$ & $\begin{array}{rr}82 & (70.1 \%) \\
48 & (41.0 \%) \\
17 & (14.5 \%) \\
8 & (6.8 \%) \\
6 & (5.1 \%) \\
9 & (7.7 \%)\end{array}$ & $\begin{array}{rr}89 & (33.2 \%) \\
142 & (52.9 \%) \\
73 & (27.2 \%) \\
59 & (22.0 \%) \\
20 & (7.5 \%) \\
20 & (7.5 \%)\end{array}$ & $\begin{array}{l}0.001 \\
\text { n.s. } \\
\text { n.s. } \\
\text { n.s. } \\
\text { n.s. } \\
\text { n.s. }\end{array}$ \\
\hline Locus 2 & $\begin{array}{l}5 \\
7 \text { group } \\
8 \\
12 \\
\text { W5 } \\
\text { LND } \\
1+8\end{array}$ & $\begin{array}{rr}2 & (1.7 \%) \\
28 & (23.9 \%) \\
94 & (80.3 \%) \\
30 & (25.6 \%) \\
12 & (10.3 \%) \\
7 & (6.0 \%) \\
77 & (65.8 \%)\end{array}$ & $\begin{array}{rc}25 & (9.3 \%) \\
119 & (44.4 \%) \\
79 & (29.5 \%) \\
91 & (33.9 \%) \\
39 & (14.5 \%) \\
31 & (11.5 \%) \\
54 & (20.1 \%)\end{array}$ & $\begin{array}{l}\text { n.s. } \\
\text { n.s. } \\
0.001 \\
\text { n.s. } \\
\text { n.s. } \\
\text { n.s. } \\
0.001\end{array}$ \\
\hline
\end{tabular}

Table I Frequency of HL-A antigens in patients with adult coeliac disease and in controls

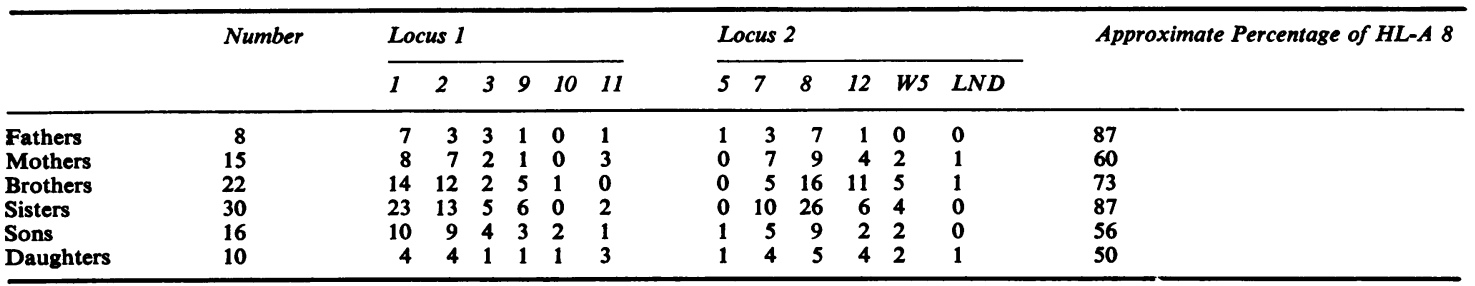

Table II Distribution of $H L-A$ antigens in relatives of $46 H L-A$ adult coeliac disease propositi ${ }^{1}$

${ }^{1}$ This table is constructed of the antigens identified in the phenotypes. Any individual homozygous for one antigen will have only three antigens to contribute. 
FAMILY I

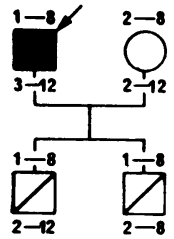

FAMILY II

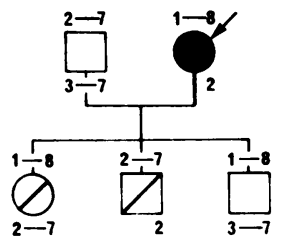

FAMILY III

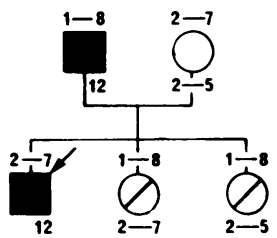

FAMILY IV

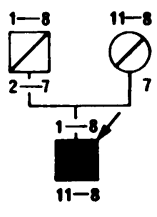

Fig 1 Figure showing the inheritance of $H L-A$ haplotypes and coeliac disease in six families.

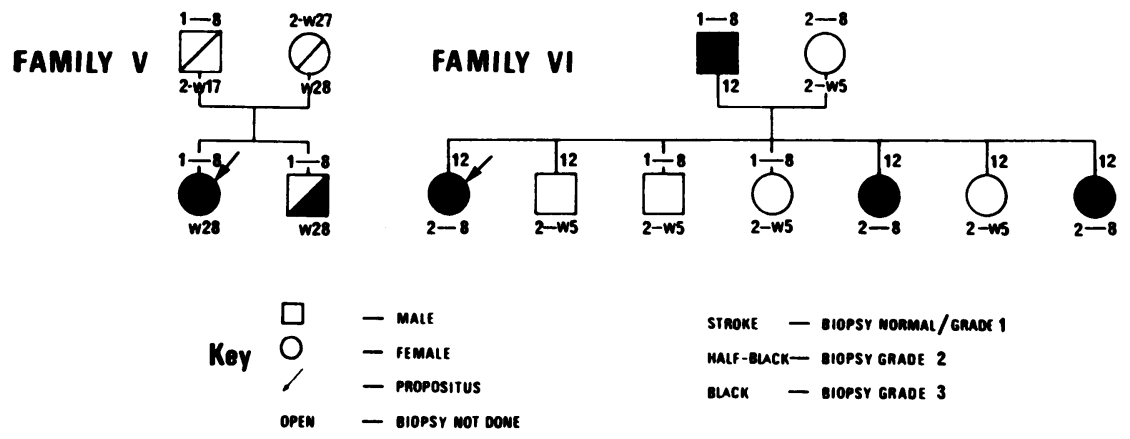

an only son who had coeliac disease. The mother who has the HL-A 8 antigen but not the 1 and 8 haplotype does not have coeliac disease. Of two siblings in family $\mathrm{V}$ who inherited the 1 and 8 haplotype from their unaffected father, one has coeliac disease while the other has the grade II abnormality (Roy Choudhury et al, 1966) in his jejunal biopsy and may or may not have coeliac disease. In family VI the father is a coeliac having the 1 and 8 haplotype. Three of his children have coeliac disease but although they all have the HL-A 8 antigen it is clear that this is part of a 2 and 8 haplotype inherited from their mother.

\section{Discussion}

We have confirmed that there is an increased frequency of the HL-A 8 and HL-A 1 antigens in coeliac patients together with an increase in the combination of HL-A 8 and HL-A 1. This combination is associated as a haplotype in a substantial number of cases. Despite the findings of these increased frequencies it is noteworthy that the inheritance of the antigens in coeliac families is straightforward and follows Mendelian principles. A criticism which may be levelled at typings of cells from individuals with a particular disease is that the demonstration of antigens can be unreliable. HL-A typing sera may contain antibodies directed against cell-surface antigens other than HL-A which can be demonstrated on abnormal cells (Dick, Steel, and Crichton, 1972; Mackintosh, Wallin, Hardy, Ling, and Steel, 1973). However, we have not found any technical difficulties in typing patients with coeliac disease and their HL-A phenotype has always been compatible with that expected from knowledge of the phenotype of their relatives.

One question that arises is whether it is the increased frequency of the HL-A 8 or HL-A 1 antigen or of the combination which has the most relevance in coeliac disease. Falchuk and coworkers (1972) suggest that the HL-A 8 antigen is of paramount importance and that the increase in the HL-A 1 antigen occurs because of the known genetic association between the two. There is some support for this view in that the HL-A 8 antigen is found more commonly in coeliac disease patients than is the HL-A 1 antigen $(80.3$ and $70.1 \%$ respectively) while their frequencies in a control population are approximately equal (29.5 and $33.2 \%$ respectively). The frequency of the combination of these two antigens in coeliac patients is $65.8 \%$ while that in controls is only $20 \cdot 1 \%$ but despite this increase the combination of these two antigens is lacking in so many coeliac patients that it seems unlikely to be of major importance. However, the evidence is not available at this time to allow a firm opinion on this matter.

The familial nature of coeliac disease was evident 
in this study and allowed analysis of the inheritance of the disease in relation to the inheritance of HL-A antigens. The information regarding the inheritance both of the HL-A 1 and 8 haplotype and of the disease itself has been summarized. Four parents who had transmitted this haplotype to their coeliac children did not have coeliac disease themselves while three other parents who similarly handed on the 1 and 8 haplotype to coeliac children did have coeliac disease. Four children inherited this haplotype from a coeliac parent but do not have coeliac disease. Thus it is clear that although the HL-A 1 and 8 haplotype is frequently found in those with coeliac disease and is inherited normally within their families, its inheritance by a member of a coeliac family need not be associated with inheritance of the disease.

We would like to thank Professor J. H. Edwards, Department of Human Genetics, University of Birmingham, for his helpful advice and criticism of the manuscript, and Dr G. W. G. Bird, Director, Birmingham Regional Blood Transfusion Centre, for his kindness in providing facilities for tissue typing. We would also like to thank Mesdames A. Carter, S. Hall, and D. Hemming for technical assistance.

P.L.S. and G.K.T.H. are in receipt of grants from the Endowment Fund of the United Birmingham Hospitals.

\section{References}

Cavalli-Sforza, L. L., and Bodmer, W. F. (1971). In The Genetics of Human Populations, p. 253. Freeman, San Francisco.

Dick, H. M., Steel, C. M., and Crichton, W. B. (1972). HL-A typing of cultured lymphoblastoid cells. Tissue Antigens, 2, 85-93.

Falchuk, Z. M., Rogentine, G. N., and Strober, W. (1972). Predominance of histocompatibility antigen HL-A 8 in patients with gluten-sensitive enteropathy. J. clin. Invest., 15, 1602-1605.

Harris, O. D., Cooke, W. T., Thompson, H., and Waterhouse, J. A. H. (1967). Malignancy in adult celiac disease and idiopathic steatorrhea. Amer. J. Med., 42, 899-912.

Lilly, F., Boyse, E. A., and Old, L. J. (1964). Genetic basis of susceptibility to virol leukaemogenesis. Lancet, 2, 1207-1209.

McDevitt, H. O., and Bodmer, W. F. (1972). Histocompatibility antigens, immune responsiveness and susceptibility to disease. Amer. J. Med., 52, 1-8.

MacDonald, W. C., Dobbins, W. O., and Rubin, C. E. (1965). Studies of the familial nature of celiac sprue using biopsy of the small intestine. New Engl. J. Med., 272, 448-456.

Mackintosh, P., Wallin, J., Hardy, D. A., Ling, N. R., and Steel, C. M. (1973). The interaction of normal lymphocytes and cells from lymphoid cell lines. IV. HL-A typing of the cell line cells. Immunology, 24, 315-331.

Miller, R. G. (1966). In Simultaneous Statistical Inference, p. 8. McGraw, New York.

Roy Choudhury, D. C., Cooke, W. T., Tan, D. T., Banwell, J. G., and Smits, B. J. (1966). Jejunal biopsy: criteria and significance. Scand. J. Gastroent., 1, 57-74.

Roy Choudhury, D. C., Nicholson, G. I., and Cooke, W. T. (1964). Simple capsule for multiple intestinal biopsy specimens. Lancet, 2, 185-186.

Stokes, P. L., Asquith, P., Holmes, G. K. T., Mackintosh, P., and Cooke, W. T. (1972a). Histocompatibility antigens associated with adult coeliac disease. Lancet, 2, 162-164.

Stokes, P. L., Asquith, P., Holmes, G. K. T., Mackintosh, P., and Cooke, W. T. (1972b). HL-A 1 and 8 in organ donors. Lancet, 2, 1024.

Terasaki, P. I., and McClelland, J. D. (1964). Microdroplet assay of human serum cytotoxins. Nature (Lond.), 204, 998-1000. 